\title{
Carcinoma of Cowper Glands
}

National Cancer Institute

\section{Source}

National Cancer Institute. Carcinoma of Cowper Glands. NCI Thesaurus. Code C39864.

An adenocarcinoma that arises from the Cowper glands. 